\title{
UMA ENTREVISTA COM EDWIN CADENA: "SOMOS MOLÉCULAS", UMA ABORDAGEM DE ENSINO PARA A PALEONTOLOGIA MOLECULAR
}

\author{
AN INTERVIEW WITH EDWIN CADENA: “WE ARE MOLECULES”, \\ A TEACHING APPROACH TO MOLECULAR PALEONTOLOGY
}

\author{
Everton Fernando Alves ${ }^{1}$
}

\section{RESUMO}

Esta entrevista foi realizada com o tafônomo molecular colombiano Edwin Cadena, um dos maiores especialistas em Paleontologia Molecular da atualidade. Suas trajetórias formativas são apresentadas nas relações com seus interesses pela Geologia e Paleontologia. Cadena nos conta sobre os desafios de combinar a Paleontologia tradicional com a Paleontologia Molecular, incluindo a paleogenômica e a paleoproteômica. Em uma conversa instigante, ele explica, na primeira parte da entrevista, o que é a Paleontologia Molecular, aspectos históricos e os objetos de estudo, a importância das pesquisas paleomoleculares e as principais técnicas utilizadas em investigações atuais. Na segunda parte da entrevista, Cadena apresenta a forma como a Paleontologia Molecular pode ser ensinada para níveis básicos da educação, como no caso do ensino fundamental e médio, e para o ensino superior em nível de graduação em Ciências Biológicas. Na última parte, Cadena explora brevemente as possíveis abordagens de investigação da Paleontologia molecular a partir da perspectiva da Educação em Ciências.

Palavras-chave: Ensino de Paleobiologia, Tafonomia Molecular, Biomoléculas antigas, Educação em Ciências.

\section{ABSTRACT}

This interview was conducted with the Colombian molecular taphonomist Edwin Cadena, one of the greatest experts in Molecular Paleontology today. His formative trajectories are presented in relation to his interests in Geology and Paleontology. Cadena tells us about the challenges of combining traditional Paleontology with Molecular Paleontology, including paleogenomics and paleoproteomics. In an instigating conversation, he explains, in the first part of the interview, what is Molecular Paleontology, historical aspects and objects of study, the importance of paleomolecular research and the main techniques used in current investigations. In the second part of the interview, Cadena presents how Molecular Paleontology can be taught for basic levels of Education, as in the case of elementary and high school, and for higher education at the undergraduate level in Biological Sciences. In the last part, Cadena briefly explores possible research approaches to Molecular Paleontology from the perspective of Science Education.

Keywords: Teaching Paleobiology, Molecular Taphonomy, Ancient Biomolecules, Science Education.

1 Entrevistador. Mestre em Imunogenética pela Universidade Estadual de Maringá (UEM), Paraná. E-mail: efalves.mga@ gmail.com 


\section{INTRODUÇÃO}

Edwin-Alberto Cadena é um geólogo-paleontólogo colombiano com experiência notável na descoberta de novas espécies fósseis, incluindo a maior cobra já encontrada (Titanoboa cerrejonensis). É bacharel em Geologia pela Universidad Industrial de Santander (1997-2003, Colômbia), mestre em Geologia pela University of Florida (2007-2009, EUA), doutor em Geociências pela North Carolina State University (2009-2012, EUA) e possui pós-doutorado pela Alexander Von Humboldt Foundation (2012-2015, Alemanha).

Atualmente, é Professor Associado do Programa de Pós-Graduação em Ciências do Sistema Terrestre e membro do Grupo de Pesquisa PaleoNeo - Paleontologia Neotropical Tradicional e Molecular da Universidad del Rosario (Bogotá, Colômbia). Também é Pesquisador Associado do Smithsonian Tropical Research Institute.

Um dos projetos que Cadena vem desenvolvendo recentemente se concentra na exploração do potencial de preservação de biomoléculas orgânicas originais em osteócitos e estruturas semelhantes a vasos sanguíneos de tartarugas do Deserto de Gobi (Mongólia), Messel Pit (Alemanha) e La Venta (Colômbia), usando espectrometria de massas e técnicas de fase de anticorpo.

Ao longo dos últimos anos, Cadena tem ensinado e preparado novos profissionais para atuarem na vanguarda das pesquisas paleomoleculares. Atualmente, orienta três alunos da graduação em fase de TCC, e na Pós-Graduação possui um aluno de mestrado e outro de doutorado, que, dentre outras abordagens, fazem investigações em Paleontologia Molecular.

Para Cadena, a combinação da Paleontologia tradicional com a Paleontologia Molecular, incluindo o ramo da Paleogenômica e da Paleoproteômica, permite abordar eventos e questões biológicas e evolutivas de uma perspectiva mais ampla, um campo que está apenas começando.

Gentilmente, o professor e pesquisador Edwin-Alberto Cadena aceitou participar desta entrevista via e-mail no dia 12/02/2021 compartilhando conosco conhecimento não só a respeito de suas pesquisas, mas também sobre perspectivas futuras relativas ao ensino da Paleontologia Molecular.

\section{Defina o campo de pesquisa da Paleontologia Molecular.}

Embora a grande maioria dos pesquisadores considere o nome "molecular" como se tratando exclusivamente da preservação de biomoléculas no registro fóssil, o que está correto, as biomoléculas, ou na grande maioria seus remanescentes (proteínas, DNA, lipídios, etc.) estão associadas à preservação das estruturas que originalmente constituem os tecidos moles (pele, fibras, vasos sanguíneos, células, entre outros).

Por isso, podemos definir a Paleontologia Molecular como o estudo da preservação excepcional dos tecidos moles e seus possíveis constituintes originais no registro fóssil. Este campo de pesquisa surgiu em meados do século passado, na década de 1950-60, com estudos principalmente 
de tecidos ou células preservados em fósseis. Pesquisadores como Pawlicki foram os pioneiros neste assunto, e, desde a década de 1990, a incorporação de novas técnicas de identificação se tornaram obrigatórias neste campo como a SEM - microscopia eletrônica de varredura, FTIR - espectroscopia no infravermelho por transformada de Fourier, Espectroscopia Raman e a Espectrometria de massas.

\section{Qual é a importância das pesquisas em Paleontologia Molecular?}

Estudos paleomoleculares abrem a possibilidade de compreender melhor o processo de fossilização em escalas incomuns na investigação tafonômica, de revisitar e explorar fósseis descritos há vários anos ou décadas atrás com uma nova perspectiva e, acima de tudo, de responder a perguntas interessantes sobre paleofisiologia, paleobiologia e outros aspectos fundamentais de organismos extintos.

\section{Temos visto que, que para investigar biomoléculas antigas, é necessário que o paleon-} tólogo molecular faça uso de instrumentos e métodos inovadores que têm trazido muito progresso para a Paleontologia. Quais são as principais técnicas?

Esta poderia ser uma resposta bem longa, mas para mantê-la curta, eu posso dizer que elas variam de técnicas convencionais como microscopia de luz transmitida, polarizada, confocal, imunologia e anticorpos, microscopia eletrônica e de transmissão e seus avanços em sensibilidade, até o avanço na instrumentação de dispositivos de análise química como espectrômetros de massa, sequenciadores, nanotomografia, entre outros. Talvez a melhor resposta seja: as técnicas são todas possíveis e estão ao alcance do paleontólogo para responder às suas perguntas de pesquisa e demonstrar a validade de suas descobertas.

4. Em sua opinião, você acha importante ensinar conceitos gerais de Paleontologia Molecular para alunos de níveis mais básicos, como ensino fundamental e médio?

Com certeza. Acredito que os achados da Paleontologia Molecular fazem parte da informação que foi preservada nos fósseis e, portanto, faz parte da sua essência, assim como estudamos sua variabilidade morfológica, sua diversidade, seu tamanho entre outros, devemos também ensinar às crianças e adolescentes que, em alguns casos, a preservação da vida passada pode atingir uma escala anteriormente impensável.

\section{Você acha importante incluir conceitos e tópicos gerais da Paleontologia Molecular nas disciplinas gerais de Paleontologia de cursos de graduação em Ciências Biológicas?}

Sem dúvida, pois é uma subárea que faz parte da Paleontologia. No entanto, durante a graduação, entendo que não é necessário um curso de um semestre inteiro sobre o assunto. Por exemplo, na Universidade em que estou afiliado, eu ensino uma disciplina geral de Paleontologia, que é assistida por alunos de todas as especializações. Nessa disciplina, eu incluo um módulo sobre Paleontologia 
Molecular. A meu ver, o quanto antes os estudantes forem expostos a tais temas, mais possibilidades eles terão de aumentar a sua curiosidade sobre o campo da Paleontologia Molecular, ainda que seja no intuito de contestar algumas das hipóteses ou dados apresentados. A Paleontologia Molecular pode auxiliar na formação de estudantes de Biologia e Paleontologia em técnicas às quais eles normalmente não teriam contato ou não conheceriam e, desse ponto de vista, torna-se uma experiência de formação mais ampla e interdisciplinar.

\section{Como é o ensino de Paleontologia Molecular para alunos de graduação em ciências} biológicas na Colômbia? Como contornar o problema da falta de ensino de Paleontologia Molecular para alunos de graduação?

Na Universidade em que leciono, eu ofereço uma disciplina geral de Paleontologia para alunos de graduação na qual separo um módulo sobre o assunto, e na pós-graduação leciono um curso específico de um semestre em Paleontologia Molecular. Porém, é um grande desafio devido à falta de instrumentação que pode haver nos países latino-americanos. Não sei se meus colegas de outras universidades ensinam essas disciplinas em seus cursos gerais, o que costumam fazer é me convidar para dar palestras para seus alunos de vez em quando, mas com certeza ainda há muito que fazer.

\section{Que abordagens poderiam ser adotadas por professores da Educação Básica ou do Ensino Superior em nível de graduação a fim para expandir e melhorar o ensino da Paleontologia Molecular para crianças e jovens?}

Poderia ser trabalhada com eles a ideia de que somos moléculas! Nosso corpo, nosso cérebro, tudo funciona graças a células e componentes orgânicos, e podemos jogar futebol porque nossos ossos são uma máquina inteligente de certa forma, e tudo isso pode ser preservado em alguns casos no registro fóssil. Esta poderia ser uma ideia de como conectar a Paleontologia Molecular com algo cotidiano dos alunos.

\section{CONSIDERAÇÕES FINAIS}

Como pôde ser visto, a Paleontologia Molecular é um campo emergente da ciência que vem chamando a atenção da comunidade paleontológica internacional. No continente Sul Americano, as pesquisas paleomoleculares estão se destacando principalmente na Colômbia a partir do trabalho pioneiro de um pesquisador ousado como o Prof. Dr. Edwin Cadena que não tem medo de inovar e incorporar na Paleontologia técnicas e instrumentais de outras áreas e fazer novas perguntas, o que há alguns anos atrás não se pensava ser possível.

Somente na última década, Cadena tem feito diversos achados de tecidos moles originais em fósseis de tartarugas, tais como os de vasos sanguíneos e osteócitos de uma tartaruga fóssil 
do Paleoceno-Eoceno da Colômbia (CADENA; SCHWEITZER, 2014), microestruturas semelhantes à osteócitos e vasos sanguíneos de ossos fósseis de espécimes de tartarugas, crocodilo e pangolim do Eoceno da Alemanha (CADENA, 2016), resíduos de proteínas originais de pele excepcionalmente preservada de um peixe fóssil do Cretáceo Inferior da Colômbia (ALFONSO-ROJAS; CADENA, 2020), osteócitos e vasos sanguíneos de ossos fósseis de tartarugas de três localidades diferentes, como do Cretáceo Superior da Mongólia, do Eoceno da Alemanha e do Mioceno da Colômbia (CADENA, 2020a), além de células ósseas em tartarugas fósseis do Paleoceno da Colômbia (CADENA, 2020b).

Tais achados se configuram como pesquisas pioneiras produzidas no Sul da América, e a partir dessas vindo muito mais por aí, pois as chances de se encontrar material orgânico preservado em fósseis estão relacionadas, dentre outros fatores, às técnicas analíticas empreendidas para análise do registro fóssil. Assim como a Colômbia, o Brasil tem grande potencial para descobertas similares no campo da pesquisa básica uma vez que possui de igual modo, um rico registro fossilífero. Ao mesmo tempo, também possui um campo inexplorado para o ensino de novidades científicas relacionadas à Tafonomia molecular e à Paleontologia Molecular a uma nova geração de professores e pesquisadores da Biologia comprometidos com o avanço da ciência brasileira.

\section{REFERÊNCIAS}

CADENA, E. A.; SCHWEITZER, M. H. A Pelomedusoid Turtle from the Paleocene-Eocene of Colombia Exhibiting Preservation of Blood Vessels and Osteocytes. Journal of Herpetology, v. 48, n. 4, p. 461-465, 2014.

CADENA, E. Microscopical and elemental FESEM and Phenom ProX-SEM-EDS analysis of osteocyte- and blood vessel-like microstructures obtained from fossil vertebrates of the Eocene Messel Pit, Germany. PeerJ, v. 4, n. e1618, 2016.

ALFONSO-ROJAS, A.; CADENA, E. Exceptionally preserved 'skin' in an Early Cretaceous fish from Colombia. PeerJ, v. 8, n. e9479, 2020.

CADENA, E. In situ SEM/EDS compositional characterization of osteocytes and blood vessels in fossil and extant turtles on untreated bone surfaces; different preservational pathways microns away. PeerJ, v. 8, n. e9833, 2020a.

CADENA, E. A. The first remains of vertebrates from the Paleocene Lisama formation, Middle Magdalena Valley Basin of Colombia. Journal of South American Earth Sciences, v. 103, n. 102745,2020 b. 